\title{
Are College Costs Worth it? How Individual Ability, Major Choice, and Debt Affect Optimal Schooling Decisions
}

\author{
Douglas A. Webber ${ }^{*}$
}

February 16, 2015

\begin{abstract}
This paper examines the financial value over the course of a lifetime of pursuing a college degree under a variety of different settings (e.g. major, student loan debt, individual ability). Using a lifecycle simulation approach, I account for ability/selection bias and the substantial probability that entering college freshmen will not eventually graduate, two critically important factors when evaluating the value of pursuing a college degree.

I find that financial proposition of attending college is an unambiguously good investment for the vast majority of individuals with low to average college costs, although majors with a lower expected return do not pay off until middle age. However, when the financial costs of attending college are high (defined here as roughly $\$ 30,000$ per year), the gains from attending college are far more tenuous, particularly among those with below median ability and those pursuing an Arts/Humanities degree. I estimate the net present discounted value of attending college to vary between $\$ 95,000$ and $\$ 275,000$ depending on the major (STEM, Business, Social Sciences, Arts/Humanities) pursued.
\end{abstract}

*Temple University Department of Economics and IZA. 1301 Cecil B. Moore Ave. Ritter Annex 883. Philadelphia, PA. 19102 Email: douglas.webber@temple.edu

$\uparrow I$ have greatly benefited from the advice of J. Catherine Maclean, Ron Ehrenberg, Matthew Freedman, and Moritz Ritter. 


\section{Introduction}

Personal debt arising from student loans has steadily risen in recent years. The most recent graduating college cohort is burdened by an average of $\$ 29,400$ in student loan debt, while the national total has surpassed $\$ 1$ trillion, a figure that some claim represents an economic bubble which could have substantial negative effects for future generations.

These numbers beg the question: Is taking on substantial student loan debt to (possibly) obtain a college degree a sound financial proposition? Unsurprisingly, this simple question has a complicated answer which depends on a variety of factors, such as the student's major, ability level, and probability of completing a degree, among many others. This paper seeks to provide the most comprehensive statistics to date on the lifecycle returns to various majors, and the implications these returns have for paying off costs associated with attending college.

In order to do this, I extend the lifecycle earnings simulation model developed by Webber (2014a) to examine the expected returns to attending college to a hypothetical high school senior. This approach allows me to estimate the length of time it takes for a college degree to become a positive financial proposition (taking into account the explicit costs associated with attending college as well as the implicit opportunity cost and uncertainty associated with completing the degree) under a wide variety of scenarios including different majors, student loan amounts, and ability levels. This approach allows me to correct for various types of selection/ability bias, as well as the fact that roughly $40 \%$ of students will not graduate within 6 years of beginning college (a critical, but often overlooked factor when evaluating the financial value of attending college).

From the perspective of a high school senior deciding whether to go to college, what to major in, and how much to pay for such an education, I find that college is almost always the right financial decision in terms of the expected value of lifetime earnings. For students with average levels of debt, the anticipated returns will, in expectation, outpace any costs by middle age or considerably earlier. The decision becomes much less clear, however, when college costs and subsequent debt are high, and in particular when examining students at the lower end of the ability distribution. For this group of students, a college degree may not pay for itself until much later in life, and depending on the major, it may never be a good financial proposition. I estimate that the net present discounted value ranges from $\$ 95,000$ to $\$ 275,000$ across the various major categories, far exceeding the costs of attending the typical public institution, but potentially falling short of the more expensive private institutions.

These findings translate to a number of policy implications. Most important among them is transparency and dissemination of the expected financial returns to recent high school graduates who are making decisions 
about their educational future. The ethos surrounding postsecondary education has increasingly become akin to "A college degree is the best outcome for everyone regardless of cost". While true for most students, the results of this paper show that this does not apply to everyone, especially when it concerns degrees with low financial returns and/or high levels of debt. The results from this paper may also be able to inform differential tuition and student loan policies.

The paper is constructed as follows: Section 2 discusses the previous literature. Section 3 describes the data used to construct the lifetime earnings trajectories. Section 4 details the empirical methodology used in the simulations. Section 5 provides a discussion of the findings and their implications, and Section 6 concludes.

\section{Previous Literature}

This paper contributes to three related literatures: the returns to education, major choice, and student loans. This section focuses mainly on the major choice and student loan literatures due to the large scope and scale of the work focusing on the returns to education. For an overview of the general returns to education, see Card (1999). For work specifically dealing with the returns to a college degree, see Averett and Burton (1996); Brewer et al. (1999); Goldin and Katz (2008); Grogger and Eide (1995); Dillon (2012) to name just a few. For recent reviews of heterogeneous returns to human capital, see Altonji. et al. (2012) or Webber (2014b).

Much of the literature on college major choice focuses on the role of expected earnings in students' decisions. Berger (1988) uses a Heckman selection framework, using family background characteristics as exclusion restrictions from the earnings equation to control for self-selection into majors and produces an estimate of the short-term expected future earnings from each degree. The predicted future earnings for each major are subsequently included in a conditional logit model of college choice, and are found to be a significant factor in students' decisions. For an excellent review of the recent work on college major choice, see Altonji. et al. (2012).

Arcidiacono (2004) uses a dynamic discrete-choice framework to estimate the impact of expected earnings on major choice. While Arcidiacono (2004) concludes that expected earnings do play a role in major choice, the estimates are smaller in magnitude than the results of Berger (1988), a finding attributed to invalid exclusion restrictions in the Berger (1988) Heckman model. In a more recent study of Duke University undergraduates, Arcidiacono et al. (2012) conclude that much of the selection into majors is due to compar- 
ative advantage. Additionally, Montmarquette et al. (2002) find a strong impact of expected earnings upon graduation from college in their model of major choice, which also accounts for relative major premiums and the likelihood of completing a given major.

Another branch of the college premium literature focuses on the differential returns to specific skills learned in college rather than majors. For example, Grogger and Eide (1995) document the importance of math ability in explaining earnings differences, decomposing this effect into both the return to math ability and the change in the composition of college graduates' field of degree. Hamermesh and Donald (2008) demonstrate that holding college major constant, there are substantial returns to taking upper-division science and math courses.

Robst (2007) provides evidence that there can be significant wage penalties for workers employed in fields different from their college major. This could lead to differences in the returns to college majors if there are differential shifts in the supply/demand for each major, thus forcing some majors to work in outside fields more than others.

Many studies which examine the returns to specific majors have focused on the returns at a specific point in time rather than across the lifecycle - typically early career earnings. A notable exception is Walker and Zhu (2011), who decompose lifetime earnings by major, but due to data constraints, they are unable to account for endogenous major choice. The empirical model in the current paper extends the work of Webber (2014a), which documented stark differences in lifetime earnings premia across majors after accounting for selection based on both cognitive and noncognitive factors. A more detailed description of the model is given in Section 4.

As regards the literature on student loans, much of the work in this field - on loans and the relative value of obtaining a college degree - is summarized in the excellent Journal of Economic Perspectives article by Avery and Turner (2012). They provide a detailed history of student loan programs in the U.S., and a wealth of statistics on student debt. The chief aim of this manuscript is to provide a more formal and in depth treatment of the helpful back-of-the-envelope calculations made in Avery and Turner (2012).

The student loan market in the U.S. is dominated by federally-backed loans ${ }^{1}$, with private student loans making up slightly less than ten percent of the market. The logic behind this substantial federal investment is often taught in most microeconomics principles courses: college-educated labor produces substantial positive externalities (i.e. public health, crime), and therefore should be subsidized ${ }^{2}$.

Students face a wide variety of options which govern the total cost and duration of a loan depending

\footnotetext{
${ }^{1}$ The four primary types are subsidized and unsubsidized Stafford loans, Perkins loans, and Parent Loans for Undergraduates (PLUS). See Avery and Turner (2012) for a detailed description of each category of loan.

${ }^{2}$ Although not all studies conclude that enhanced student loan availability has a large impact on college enrollment (Nielsen et al., 2010).
} 
on the type and source (federal or private). These include interest rates, borrowing caps, and repayment flexibility. Repayment plans typically vary between 10 and 25 years, with repayment schedules that can be fixed, graduated, or income-contingent ${ }^{3}$.

Another strand of the student loan literature examines the impact of financial aid policy on college persistence and the transition into the labor market. DesJardins et al. (2002) estimate the impact of a number of different student loan/scholarship policies on retention and graduation. Rothstein and Rouse (2011) analyze a natural experiment arising from one university's financial aid policies. They note that high levels of student debt cause graduates to alter their occupational choices, choosing higher paying jobs over "public interest" jobs.

Related to the question of whether, and for whom, college is worth the investment is the question of who defaults on student loans. Dynarski (1994) provided the first detailed evidence on this subject, finding unsurprisingly that borrowers from low-income households, college dropouts, and those with the lowest postcollege earnings were the most likely to default on their student loans. The more recent study by Hillman (2014) finds many of the same results as Dynarski (1994) for the current cohort of college students. Ionescu (2009) tests the impact of various student loan policies (e.g. repayment flexibility, eligibility requirements) on schooling decisions and default rates using a structural model of human capital accumulation.

\section{Data}

The data used in the lifecycle earnings simulation are collected from several sources: the National Longitudinal Survey of Youth 1979 and 1997 waves (NLSY79 and NLSY97); the 2012 American Community Survey (ACS); and the 1993 and 2003 waves of the National Survey of College Graduates (NSCG).

The NLSY79 is a panel dataset which began surveying 12,686 individuals annually between 1979 and 1994 and biennially between 1994 and the present. All respondents were between the ages of 14 and 22 during the initial survey year of 1979. The NLSY is quite broad in its scope of survey questions, and has been used countless times in the economics literature. It was designed in part to track the transition from school to work, and thus is well-suited for the current study. One of the most appealing attributes of the NLSY is the availability of cognitive ability measures. The Armed Forces Qualification Test (AFQT) is a composite percentile rank of four subsections of the Armed Forces Vocational Aptitude Battery (ASVAB): word knowledge, paragraph comprehension, arithmetic reasoning, and mathematics knowledge. Given its construction, the AFQT is comparable to standard college entrance test scores. The NLSY79 also contains

\footnotetext{
${ }^{3}$ For an overview of income-contingent loans, see Krueger and Bowen (1993)
} 
data on two commonly used measures of noncognitive ability, the Rotter Scale which gauges locus of control and the Rosenberg Self-Esteem Score. An individual with a high score on the Rotter Scale believes their actions have little impact on the quality of their life, and has commonly been used as a measure of noncognitive skill in the labor literature (Osborne-Groves, 2005; Heckman et al., 2006). The Rosenberg Scale represents an individual's assessment of their self-esteem or self worth. While it is less commonly used than the Rotter Scale, it is also seen as a viable measure of noncognitive abilities in the education and labor literatures (Murnane et al., 2001; Heckman et al., 2006). As discussed in Heckman et al. (2006), these variables are important components of the education selection mechanism. Since the measures of cognitive and noncognitive ability were measured only once for each individual between 1979 and 1981, I must make the assumption that the economic impact of these qualities remains relatively constant over time. Fortunately, recent research supports this assumption (Cobb-Clark and Schurer, 2013).

The NLSY97 is constructed in a similar way to the NLSY79 except that it focuses on a more recent cohort (12 to 16 years old as of December 31, 1996). The NLSY97 does not contain the Rotter or Rosenberg results, but instead includes substantially more information on personality traits, attitudes, and expectations about life. The models which use the NLSY97 data use each item of the Ten Item Personality Inventory ${ }^{4}$ to control for noncognitive skills.

The ACS is a large-scale nationally representative survey which is designed to replace the decennial long-form Census. It provides data on more than 3 million individuals every year, and allows for much finer geographic identifiers than any other national survey. The appeal of using the ACS as opposed to other national surveys is twofold. First, the ACS recently began asking respondents their major field of study if they attended college. Second, the large sample sizes for even the narrowest age group and major category bins allows for the precise estimation of regression coefficients. The data for the current study are taken from the 2012 ACS.

The NSCG is a survey of individuals with at least a bachelors degree conducted by the National Science Foundation. I utilize the 1993 and 2003 waves of the NSCG to obtain information on the relative returns to different majors at points in time not covered by the ACS.

Six educational outcomes examined in this paper: high school graduates with no college experience, some college but no four-year degree, and four-year degrees in science, technology, engineering, or math (STEM), business, social science, and arts/humanities. These categories are chosen to be broad enough to estimate precise differences in both the NLSY, NSCG, and ACS parameters. A complete accounting of each major can be found in the NLSY documentation ${ }^{5}$. Below are the major category groupings which I include in each

\footnotetext{
${ }^{4}$ See Gosling et al. (2003) for further details.

${ }^{5} \mathrm{http:} / /$ www.nlsinfo.org/content/cohorts/nlsy79/other-documentation/codebook-supplement/nlsy79-attachment-4-fieldsstudy. Access date 4/20/2014
} 
bin for the purposes of this paper:

STEM - Biological Sciences, Computer and Information Sciences, Engineering, Mathematics, Physical Sciences

Business - Business and Management

Social Science - Social Sciences, Psychology

Arts and Humanities - Theology, Letters, Library Science, Fine and Applied Arts, Foreign Languages, Architecture

This list is certainly not collectively exhaustive, and thus all majors not included in the above fields are categorized as "other" and included in each regression model as such. The "other" category includes majors such as military science, education ${ }^{6}$, area studies, or interdisciplinary studies. This paper does not report results for the "other" category because of the dissimilar nature of the degrees contained in that group, however it is important to include this outcome as a regressor in each model so that each of the college-level educational outcomes are collectively exhaustive.

\section{Empirical Methodology}

This paper constructs a lifecycle earnings simulation model which allows for the computation of estimates of the age where a particular college degree's value overtakes the explicit (tuition and student loans) and implicit (opportunity cost of time spent in college) costs of getting that degree. Further, the model takes into account selection into college and specific majors based on cognitive and noncognitive factors and allows for one to look at heterogeneity across different levels of cognitive ability. The model is based on the approach by Webber (2014a). Since the process described below contains a number of steps and datasets, I begin with a broad overview of the procedure.

In essence, I wish to estimate, for each year of an individual's working life, what the returns to a given major are. The NLSY samples allow me to (arguably) get close to such estimates by controlling for detailed personal characteristics and skills. The problem here is that the samples are of only modest size, and I am constrained to a specific cohort. By contrast, the ACS and NSCG samples are very large, and provide more recent data. But I do not have access to the detailed controls of the NLSY, and estimates of the returns to majors from the ACS and NSCG are certainly (upward) biased due to selection into college and into certain

\footnotetext{
${ }^{6}$ Education was not studied as a major category in this paper because many states require some postgraduate work to be certified as a teacher long-term. Including individuals with post-graduate work would introduce a large degree of endogeneity into the estimates due to selection. Not including these individuals but still looking at education majors would produce a. substantial underestimate of the returns to an education degree.
} 
majors. My solution is to estimate the degree of selection bias from the NLSY samples, and then to use those bias estimates to adjust the coefficients I estimate from the larger and more recent datasets.

The goal is to produce an expected lifetime earnings trajectory for each educational outcome for the most recent cohort of graduates possible. This is difficult because the oldest of individuals born between, say, 1975-84 are not yet even 40. But pooling together all birth cohorts obscures the fact that the returns to different majors and selection into college and majors have likely changed drastically over time, and would therefore be less useful to policymakers who care about current students.

I deal with this issue by using the NLSY97 to estimate the selection parameters and taking only those born after 1975 from the ACS and NSCG data to estimate the unadjusted earnings premia up to age 35 . I then use older cohorts age profiles and selection parameters to estimate the shape of lifetime earnings after age 35 (i.e. peak, rate of increase, rate of decline), but keep the young cohorts level trajectory.

\section{Magnitude of Self-Selection}

Both cognitive and noncognitive abilities play a large role in the choice of college major (Heckman et al., 2006). Given the strong positive link between these factors and wages, failure to account for cognitive and noncognitive measures will lead to an overstatement of the returns to education. The NLSY's detailed set of variables provides the ideal setting to measure the magnitude of this self-selection.

Using both the NLSY79 and NLSY97 samples, the following regressions are estimated:

$$
y_{i j}=\alpha_{0}+\alpha_{1} A_{g e} e_{i j}+\alpha_{2} \text { Black }_{i}+\alpha_{3} H i s p_{i}+\alpha_{4} \text { Gender }_{i}+E d u c_{i} \gamma+\varepsilon_{i j}
$$

$$
y_{i j}=\beta_{0}+\beta_{1} \text { Age }_{i j}+\beta_{2} \text { Black }_{i}+\beta_{3} H_{i s p_{i}}+\beta_{4} \text { Gender }_{i}+\beta_{5} A F Q T_{i}+\text { Noncognitive }_{i} \pi+\text { Educ }_{i} \delta+\varepsilon_{i j}
$$

The subscript $\mathrm{i}$ indexes individuals while $\mathrm{j}$ indexes age groupings. Thus, separate regressions are run for each of the following 6 age groups: 18-25, 26-30,31-35, 36-40, 41-45, 45+ in the NLSY79 and 2 age groups: $18-25,26-30$ in the NLSY97. The regressions are run separately by age grouping rather than by each individual age to more precisely estimate each coefficient. The dependent variable is the natural $\log$ of the prior year's income from wages and salary. The variable age enters linearly into each regression to account for earnings growth or decline within each age category. Since the objective of this paper is to quantify the lifetime earnings premium of obtaining a given type of college degree (in other words to get as close as 
possible to the value of obtaining a given degree if a high school graduate on the margin of going to college exogenously received that degree) all individuals without a high school diploma or with any postgraduate work are excluded from all analyses. As a result of these sample restrictions, having a high school diploma but never attending college is the omitted education category. Thus, educ is a vector of mutually exclusive and collectively exhaustive (except for the base category: high school graduates) educational outcomes. This includes indicators for college attendance but no degree, and a full compliment of college degree types (STEM, Social Sciences, Business, Arts and Humanities, and Other). AFQT represents the percentile rank of the individual's score on the Armed Forces Qualifying Test ${ }^{7}$. Noncognitive is a vector of variables measuring noncognitive skills including the Rotter Scale, Rosenberg Scale, mother's education, and the Ten Item Personality Inventory (See the data section for a more detailed discussion of these measures). These controls are meant to proxy for traditionally unobserved ability, both cognitive and noncognitive, and represent the only difference between the two equations. These variables are all potentially important since both cognitive and noncognitive abilities have been found to play a large role in the choice of college major (Heckman et al., 2006). As previously noted, the cognitive and noncognitive ability scores were measured only once, and thus these variables are assumed to remain relatively constant over time (an assumption supported by Cobb-Clark and Schurer (2013)). Additionally, the AFQT scores are normalized by the age at which the test was taken to account for age-related bias (Heckman et al. (2006)).

The relatively parsimonious nature of Equations (1) and (2) is intentional, and is meant to avoid controlling for factors which are outcomes of educational choice but also influence earnings. For example, industry and occupation are often outcomes of major choice, and their inclusion in the model would therefore bias the estimated major premia. Thus, only a basic set of pre-market factors are included in each model.

Taking the difference of the corresponding education coefficients from each model (i.e. $\delta_{\text {Selection }}^{S T E M, j}=$ $\left.\gamma_{S T E M, j}-\delta_{S T E M, j}\right)$ yields an estimate of the selection bias usually present when we estimate education earnings premia. These selection biases will be used later to adjust estimated earnings premiums from the ACS, which have no suitable proxies for ability. This method of estimating selection bias has been utilized elsewhere in the literature on the returns to college and ability, notably in Taber (2001).

The use of the AFQT percentile is attractive because of its straightforward construction and interpretation (e.g. moving up one percentile in the ability distribution). While this measure is certainly not a perfect

\footnotetext{
7 I experiment with the control variables entering into the model in various less parametric functional forms (e.g. including higher order polynomials, dummy variables for each AFQT decile, etc.). There was little difference in the estimated education parameters across these specifications. The results presented in this paper are therefore based on the most parsimonious model where each variable enters linearly into the log earnings regressions; however, other results are available upon request.
} 
barometer of cognitive ability, it explains roughly ten percent of the variation in yearly income all by itself ${ }^{8}$ and is a mainstay in the education literature.

I estimate two other models on the NLSY sample which yield information on several types of selection which can be built into the simulation model. First, an ordered logit which estimates the contribution of AFQT percentile to the likelihood of attending and completing college:

$$
P\left(e d u c_{i}=k\right)=P\left(c_{k-1}<X_{i} \beta<c_{k}\right)
$$

Where education may take on three values (high school diploma without any college, some college without a degree, any college degree), $\mathrm{X}$ is a vector consisting of race, ethnicity, AFQT score, Rotter Scale, Rosenberg Self-Esteem Score, and mother's education. Each $c_{k}$ represents a cutpoint (by convention, $c_{0}=-\infty$ and $\left.c_{k}=\infty\right)$.

Second, I estimate a multinomial logit of the contribution of AFQT percentile to major choice conditional on earning a college degree:

$$
P(\text { major }=k)=\frac{e^{X \beta^{(k)}}}{\left.1+\sum_{k=1}^{5} e^{X \beta^{(k)}}\right)}
$$

Where in this case $\mathrm{k}$ varies between the 5 major choices studied (Social Sciences, Business, STEM, Arts and Humanities, and Other), $\mathrm{X}$ is a vector consisting of race, ethnicity, AFQT score, Rotter Scale, Rosenberg Self-Esteem Score, and mother's education. As in all multinomial logit estimations ${ }^{9}$, the coefficients for one outcome (in this case Other) are normalized to zero.

The results from these two models are used in the earnings simulation to determine the level and major (if the individual is assigned to be a college graduate) of each individual. This allows ability to impact future earnings through a number of flexible pathways.

\section{Unadjusted earnings paths}

Using the 2012 ACS, 1993 NSCG, and 2003 NSCG, Equation (5) is run for each of 9 age groups (18-25, $26-30,31-35,36-40,41-45,46-50,51-55,56-60,61-64):$

$$
y_{i j}=\check{\beta}_{0}+\check{\beta}_{1}^{(j)} a g e_{i j}+\check{\beta}_{2} \text { Black }_{i}+\breve{\beta}_{3} H i s p_{i}+\breve{\beta}_{4} \text { Gender }_{i}+\check{\delta}_{e d u c_{i}}+\varepsilon_{i j}
$$

\footnotetext{
${ }^{8}$ Author's calculation based on regression sample used for this paper.

${ }^{9}$ The multinomial logit estimator also imposes the well-known Independence of Irrelevant Alternatives (IIA) assumption. Montmarquette et al. (2002) provides evidence that this assumption is satisfied for applications to college major choice.
} 
Where the dependent variable is the natural log of prior year earnings, and all independent variables are defined as described above. The coefficient on each education category within each age grouping, as well as the variance of residual $\log$ earnings, $\sigma_{e d u c, j}^{2}$, for each education category and age grouping are saved. Additionally, I save the mean and variance of log wages for workers with only a high school diploma to use as a baseline to compare the major premia.

\section{Life-Cycle Earnings Simulation}

Normal cumulative distribution functions (CDFs) are generated for each educational outcome (High school graduate without any college, some college without degree, and each major type) and age grouping is based on the coefficients from Equation (5) and the variance of the residuals from each group.

Finally, a dataset is populated with 100,000 simulated workers who are randomly assigned an ability level (1-100) and two uniform random shocks (one to go with the ordered logit and one for the multinomial logit).

An individual is assigned a schooling level (high school, some college, or college degree) based on the parameters estimated from the conditional logit as well as the ability and the first random shock values. Those with conditional logit scores in percentiles 64-100 of the distribution are assigned to have completed their degree in 4 years, 54-64 in 5 years, and $44-54$ in 6 years. These numbers were chosen to match recent four, five, and six-year graduation rates from U.S. four-year institutions (IPEDS).

For those assigned to be college graduates, the coefficients on AFQT from the multinomial logit run on the NLSY sample are used in conjunction with the other random shock to assign a major to each graduate.

Log earnings are then simulated for each year of labor force participation (18-64 for high school graduates, 20-64 for those with some college, and between 22-64 and 24-64 for those with a college degree depending on the ordered logit score) based on the following equation:

$$
\hat{y}_{i t}=\bar{y}_{j}^{H S}+\check{\delta}_{j}^{e d u c}-\delta_{\text {Selection }}^{\text {educ,j}}+\check{\beta}_{a g e}^{(j)}\left(t-a \bar{g} e_{j}\right)+\check{\beta}_{A F Q T}^{(j)}(a b i l i t y-50)+f^{-1}\left(\sigma_{\text {educ }, j}^{2}\right) \forall t \in j
$$

Equation (6) describes the simulated log earnings for individual $\mathrm{i}$ at each age $\mathrm{t}$. The first term on the right hand side is the average log earnings of high school graduates with no college enrollment in age group $\mathrm{j}$. The second term, $\check{\delta}_{j}^{\text {educ }}$, represents the estimated premium from the ACS and NSCG for each educational category other than high school graduates (some college, and each of the major categories) in age group $\mathrm{j}$. $\delta_{\text {Selection }}^{\text {educ } j}$ represents the magnitude of selection for each educational category in age group $\mathrm{j}$ as estimated via the NLSY. The fourth term adjusts the simulated earnings for age differences within each age group 
j. This simply accounts for the fact that there are returns (positive or negative) to age/experience within small age groupings without the loss of precision associated with estimating age effects for every age. The next term creates dispersion based on the assigned ability score and the estimated coefficient on $A F Q T$ from each age-group specific regression on the NLSY sample. The final term, the inverse normal CDF for each educational category and age grouping, generates dispersion in the simulated log earnings distribution based on the observed residual variation from the ACS and NSCG samples. Since the NLSY79 has very few respondents over the age of 50, the selection parameters for the oldest age group are estimated on a pooled sample of all observations age 45 and up. This set of parameters is then applied to each of the four oldest ACS and NSCG age groups. As described above, I use only those estimated parameters generated from a sample born after 1975 for to populate earnings for ages 35 and below. For ages above 35, I use the older cohorts to determine the shape of the earnings paths and the differences between the pre-35 parameters to set the level of earnings. Essentially, this makes the assumption that the slope and peak of the earnings paths are similar across cohorts.

Once simulated earnings paths are generated, it is trivial to add other features to the model such as tuition costs, student loan repayments, or discounted future earnings. I model student loan repayment according to the President Obama's June, 2014 executive order (set to take effect December 2015) which sets student loan monthly payments at ten percent of discretionary income ${ }^{10}$.

One final important point to consider is that when evaluating the decision of whether to attend college, simply comparing the expected college or major premia (even if able to convincingly adjust for selection bias) to the earnings of an individual with only a high school diploma will necessarily overstate the value of attending college. This is because less than 60 percent $^{11}$ of full-time first-year freshman will graduate with a degree within six years of beginning college. A more useful statistic would calculate the expected value of attending college, which is the average of earnings from those individuals who completed their college degrees and those who did not, weighted by their respective shares in the population. Since I do not have precise dropout statistics across majors, the results presented below, which incorporate this uncertainty around graduating, assume that the college non-completion rate is constant across degrees.

\footnotetext{
${ }^{10}$ The difference between current income and the poverty line. For the purposes of this paper, I use the poverty line for single adults with no dependents, or $\$ 11,670$ in 2014 dollars.

${ }^{11}$ Source: Integrated Postsecondary Education Data System (IPEDS)
} 


\section{Results}

Table 1 reports summary statistics for the NLSY, ACS, and NSCG samples. The large discrepancies in observable characteristics, particularly education, are due to the NLSY survey being administered on average at younger ages, and to an earlier cohort than the ACS/NSCG sample. This is not problematic for my estimation strategy, as described above, since I use data on the most recent birth cohort (1975-84) to estimate the level of lifecycle earnings, and only rely on older cohorts to construct the shape of earnings paths for predicted earnings in later ages (which cannot be observed since they have not yet occurred).

Table 2 shows the expected value of lifetime earnings of the median individual with various types of education and under a variety of different circumstances. As previously noted, these figures do not represent the actual earnings that a college graduate would make over his or her career ${ }^{12}$, but rather expected values, which take into account the possibility that roughly $40 \%$ of students will not graduate from college in six years. These figures are therefore of much greater relevance to a hypothetical high school senior deciding whether to attend college and what to major in than the simple college/major premia which are typically reported. The second row in Table 2 presents expected lifetime earnings with the estimated ability premium removed $^{13}$. The difference between earnings in columns (2)-(5) and column (1) represent the additional expected value of each educational outcome over a high school diploma for the median individual in the population, assuming that a college education is completely free. Figures 1 and 2 show cumulative earnings (assuming no explicit college costs) without and with the selection correction.

The final two rows illustrate how expected earnings decrease once college costs are included in the simulation model. Average college costs include $\$ 29,400$ of debt at graduation subject to a $3.4 \%$ interest rate, and roughly $\$ 4,000$ per year spent in college as costs which were not financed by a student loan. These figures are chosen to match recent debt, government student loan rates, and average public net tuition/fee statistics from the College Board (2014). The high college costs include $\$ 60,000$ in average debt at graduation subject to an interest rate of $11 \%$, and roughly $\$ 15,000$ per year spent in college as costs which were not financed by a student loan. This level of debt corresponds roughly to the 90th percentile of student loan debt with an interest rate offered by a private bank, and the costs correspond to a school with a net cost of $\$ 30,000$ per year.

Notably, all major categories have an expected return considerably greater than a high school degree, even after considering the uncertainty of completing a degree. This holds for virtually the entire domain of college costs individuals could face. Figure 3 shows expected cumulative earnings of the median individual

\footnotetext{
12 See Webber (2014a) for these figures.

${ }^{13}$ See Webber (2014a) for robustness checks and a more thorough treatment of the relationship between ability/selection bias and major choice.
} 
under the average college costs scenario, and Figure 4 depicts the high cost simulation.

While Table 2 indicates that attending college is always a good proposition for the median individual, those lower in the ability distribution may face a more uncertain decision. Table 3 displays expected earnings for those at the 25 th percentile of the ability distribution ${ }^{14}$. Each major category is still a better proposition than a high school diploma alone, however the magnitude of the premia is significantly smaller. The expected value premia range from $\$ 250,000$ for Arts/Humanities to $\$ 600,000$ for STEM/Business majors assuming average college costs. Assuming high costs, however, leads to only a very small lifetime premia for Arts/Humanities majors.

The results from Table 3 imply that on average, most college degrees are a good financial proposition for even relatively low ability individuals. However, a number of factors may swing this calculation in the other direction. First and foremost, as illustrated in Table 3, is costs. The relationship between cost and college quality can be fairly tenuous, particularly among some private colleges. Among lower ability workers, taking out substantial debt to finance a college degree, particularly one without large financial returns, does not have the financial payoff likely hoped for. Majoring in a STEM field while also paying high college costs has an expected premium of less than $\$ 200,000$, while the expected return on a similar Arts/Humanities degree is actually negative for those at the 25 th percentile of the ability distribution.

Furthermore, there is substantial heterogeneity in the returns of specific majors within the broad groups presented in this paper. Biology majors earn premia that is in line with Arts/Humanities majors, and Economists are out-earned only by select STEM engineering/computer science majors. Additionally, there are likely heterogeneous returns across school quality or institution type (Dale and Krueger, 2011; Hoekstra, 2009) which make the decision to heavily finance college a losing proposition at an institution with lower returns.

Another point to consider when evaluating the decision of whether, and how much, to pay for a college education, is how long it takes for the expected value of a college degree to exceed that of a high school diploma. Tables 4 presents the age at which each major category's cumulative expected earnings equate to the expected value of a high school diploma (net of all college costs). Average and high college costs are defined in the same way as in Tables 2 and 3.

Assuming low to average college costs, most degrees pay for themselves by a fairly early age. An individual at the median of the ability distribution is expected to have made up for all college costs (explicit costs plus opportunity cost of time spent in college and not in the labor force) by their early to mid thirties, regardless of degree. The expected breakeven age for an Arts/Humanities major at the 25th percentile of the ability

\footnotetext{
${ }^{14}$ The proportion of students who graduate is altered for these models based on the relationship between $\mathrm{AFQT}$ and the probability of graduating college conditional on having some college experience in the NLSY97. The assumed graduation rate for these students is $45 \%$.
} 
distribution is 39 , assuming average costs. Thus, even assuming a high degree of discounting for future earnings, the average cost of college is more than made up for early in life for the vast majority of the population.

As with Table 2 and 3 , the decision of whether to finance a college degree becomes murky when the costs are high, especially for those with lower innate ability. A college degree does not become a positive proposition for the median individual until middle age when paying relatively high college costs, with breakeven ages of 42, 41, 46, and 61 for STEM, Business, Social Science, and Arts/Humanities majors respectively. For those at the 25 th percentile of the ability distribution, the breakeven ages are 47,46 , and 55 for STEM, Business, and Social Science (the prospect of an Arts/Humanities degree never reaches the breakeven point under the high cost scenario).

Moderate discounting of future earnings (or virtually any discounting in the case of Arts/Humanities) would appear to eliminate most or all of the college major premium when having to pay substantial college costs. As a caveat to these results, remember that all numbers in this manuscript represent expected values, and thus some individuals will do better (those who graduate), while others will do much worse (those who fail to graduate). Further, these numbers only reflect returns in the form of salary. To the degree that there are greater nonmonetary returns (i.e. better benefits, more favorable workplace characteristics, etc.) to a college degree over high school, these results will understate the value of a degree. As a final caveat, it is certainly true that different people will receive vastly different levels of satisfaction from the careers that each degree opens up to them. The results in this paper are meant to capture only the financial returns, and are thus of the greatest benefit to those whose nonmonetary preferences are similar between given educational choices. The results are similar when the models are estimated separately by gender as shown in Appendix Tables 1-3 (Males) and Appendix Tables 4-6 (Females).

To get a sense of how discounting affects the financial value of each major category, Table 5 reports the net present discounted value at age 65 of each degree relative to the typical high school graduate. A discount rate of three percent is chosen to correspond roughly to the current expected inflation rate. The present values for the median individual range between $\$ 95$ thousand for an Arts/Humanities diploma to $\$ 260-\$ 270$ for STEM/Business degrees. Notably, these values are all substantially greater than the cost of attending the typical public university, and all but Arts/Humanities diplomas are worth more than the cost of attending an expensive private institution. The estimated values for individuals at the 25 th ability percentile are lower, ranging from $\$ 70$ thousand to $\$ 160$ thousand, but are still clearly worth a modest investment. Looking within each panel, the importance of accounting for both ability/selection bias and the likelihood of not graduating is noticeable. Failing to incorporate these corrections leads to a sizable overestimate of the value of a degree (\$130,000-\$270,000depending on the major). Comparing the top and bottom panels, it becomes 
clear that the value of a college degree is increasing in ability ${ }^{15}$.

It is also important to note that, in many of the scenarios illustrated in the tables, college is clearly a sound financial investment because of the long time horizon assumed in this model. The financial calculus is likely to be much different when analyzing the education decisions of non-traditional students who are entering or returning to college later in life, and thus have a shorter period of time to recoup their costs.

A final way to analyze the financial risk/return associated with educational choices is to examine the likelihood that a given degree will pay itself off. This is important given the substantial heterogeneity in returns we observe in the labor market due to a variety of factors (e.g. school quality, specific major, luck). Figure 5 plots the probability of cumulative earnings (net of costs) being greater than the median earnings of a high school graduate under the high cost scenario (The median high school graduate is included in the figure as a reference). The proposition of the average STEM or Business degree is predicted to be a positive financial proposition for roughly $80 \%$ of prospective students. The other major groupings do not fare quite as well, with prospective Social Science degrees paying for themselves $58 \%$ of the time, and Arts/Humanities only $45 \%$.

\section{Conclusion}

This paper attempts to provide some of the most comprehensive evidence to date on the question of whether, and for whom, a college degree is worth the investment. I evaluate the role of innate ability, student debt, and major choice on the expected value of a college degree. Using a methodology which simulates lifetime earnings trajectories, while also addressing selection bias into college and across majors, I produce estimates of the expected value of a college degree under various scenarios which are relevant to a graduating high school senior making college decisions. Furthermore, I produce estimates of the breakeven age, the age at which the added value of a college degree outweighs the explicit (e.g. tuition, debt, etc.) and implicit (opportunity cost of time spent out of the labor force) costs of attending college, under a variety of ability, debt, and major permutations.

I find that attending college is a good financial proposition under most scenarios, even when taking into account the uncertainty of actually completing a degree. For an individual with average ability, the value added of the vast majority of majors is worth well beyond the typical costs associated with a four-year public institution. Even for students at lower levels of ability (25th percentile), most degrees are worth the usual investment. However, those lower ability students who pay substantially more than the average college costs

\footnotetext{
${ }^{15}$ This is not a new finding; see, for instance Martins and Pereira (2004)
} 
may not see their investment pay off until much later in life, and depending on their major the degree may never pay itself off.

The figures presented above imply a variety of potential policy implications. First and foremost is the need to provide added transparency and information to students. The substantial heterogeneity in outcomes across the hypothetical scenarios examined underscores that decisions made by students at age 18 can have drastic and far-reaching effects on their financial well-being later in life. Young adults are often told that college is the best path to financial success, but nothing about how that potential success varies by degree and ability, or whether taking out massive debt might not be worth it.

Colleges looking to implement differential tuition policies, a growing trend, can use these figures as guidance in setting the magnitude of the tuition differences across majors. Banks are currently prohibited from charging different interest rates by major; however, the statistics generated in this paper imply substantial differences in risk across individuals which could be utilized to more efficiently price student loans. In fact, the student loan system may be an effective vehicle to remedy the information problem described above. It should be noted that depending on the goals of society/private banks, arguments can be made both in favor of increasing or reducing subsidization of certain majors. If there is a compelling public interest in having more of a given major, but this major has lower projected lifetime earnings, then the figures presented in this paper can inform policymakers as to how much of an incentive needs to be provided to induce students to change their majors.

\section{References}

J. Altonji., E. Blom, and C. Meghir, "Heterogeneity in human capital investments: High school curriculum, college major, and careers," Annual Review of Economics, vol. 4, pp. 185-223, 2012.

P. Arcidiacono, "Ability sorting and the return to college major," Journal of Econometrics, vol. 121(1-2), pp. 343-375, 2004.

P. Arcidiacono, V. Hotz, and S. Kang, "College major choice using elicited measures of expectations and counterfactuals," Journal of Econometrics, vol. 166(1), pp. 3-16, 2012.

S. Averett and M. Burton, "College attendance and the college wage premium: Differences by gender," Economics of Education Review, vol. 15(1), pp. 37-49, 1996.

C. Avery and S. Turner, "Student loans: Do college students borrow too much-or not enough?" Journal of Economic Perspectives, vol. 26(1), pp. 165-192, 2012.

M. Berger, "Predicted future earnings and choice of college major," Industrial and Labor Relations Review, vol. 41(3), pp. 418-29, 1988.

D. Brewer, E. Eide, and R. Ehrenberg, "Does it pay to attend an elite private college? cross-cohort evidence on the effects of college type on earnings," Journal of Human Resources, vol. 34(1), pp. 104-123, 1999. 
D. Card, The Causal Effect of Education on Earnings, ser. Handbook of Labor Economics. Elsevier, 1999, vol. 3, ch. 30, pp. 1801-1863.

D. Cobb-Clark and S. Schurer, "Two economists musings on the stability of locus of control," 2013, forthcoming, Economic Journal.

S. Dale and A. Krueger, "Estimating the return to college selectivity over the career using administrative earnings data," National Bureau of Economic Research Working Paper, vol. June, p. 17159, 2011.

S. DesJardins, D. Ahlburg, and B. McCall, "Simulating the longitudinal effects of changes in financial aid on student departure from college," Journal of Human Resources, vol. 37(2), pp. 653-679, 2002.

Dillon, "The college earnings premium and changes in college enrollment," 2012, manuscript.

M. Dynarski, "Who defaults on student loans? findings from the national postsecondary student aid study," Economics of Education Review, vol. 13(1), pp. 55-68, 1994.

C. Goldin and L. Katz, The Race between Education and Technology. Cambridge, MA: Harvard University Press, 2008.

S. Gosling, P. Rentfrow, and W. Swann, "A very brief measure of the big five personality domains," Journal of Research in Personality, vol. 37, pp. 504-528, 2003.

J. Grogger and E. Eide, "Changes in college skills and the rise in the college wage premium," Journal of Human Resources, vol. 30(2), pp. 280-310, 1995.

D. Hamermesh and S. Donald, "The effect of college curriculum on earnings: An affinity identifier for nonignorable non-response bias," Journal of Econometrics, vol. 144(2), pp. 479-491, 2008.

J. Heckman, J. Stixrud, and S. Urzua, "The effects of cognitive and noncognitive abilities on labor market outcomes and social behavior," Journal of Labor Economics, vol. 24(3), pp. 411-482, 2006.

N. Hillman, "College on credit: A multilevel analysis of student loan default," The Review of Higher Education, vol. 37(2), pp. 169-195, 2014.

M. Hoekstra, "The effect of attending the flagship state university: A regression discontinuity approach," The Review of Economics and Statistics, vol. 91(4), pp. 717-724, 2009.

F. Ionescu, "The federal student loan program: Quantitative implications for college enrollment and default rates," Review of Economic Dynamics, vol. 12(1), pp. 205-231, 2009.

A. Krueger and W. Bowen, "Policy watch: Income-contingent college loans," Journal of Economic Perspectives, vol. 7(3), pp. 193-201, 1993.

P. Martins and P. Pereira, "Does education reduce wage inequality? quantile regression evidence from 16 countries," Labour Economics, vol. 11(3), pp. 355-371, 2004.

C. Montmarquette, K. Cannings, and S. Mahseredjian, "How do young people choose college majors," Economics of Education Review, vol. 21(6), pp. 543-556, 2002.

R. Murnane, R. Willett, M. Braatz, and Y. Duhaldeborde, "Do different dimensions of male high school students' skills predict labor market success a decade later? evidence from the nlsy," Economics of Education Review, vol. 20(4), pp. 311-320, 2001.

H. Nielsen, T. Sorensen, and C. Taber, "Estimating the effect of student aid on college enrollment: Evidence from a government grant policy reform," American Economic Journal: Economic Policy, vol. 2(2), pp. $185-215,2010$.

M. Osborne-Groves, "How important is your personality? labor market returns to personality for women in the us and uk," Journal of Economic Psychology, vol. 26(6), pp. 827-841, 2005. 
J. Robst, "Education and job search: The relatedness of college major and work," Economics of Education Review, vol. 26(4), pp. 397-407, 2007.

J. Rothstein and C. Rouse, "Constrained after college: Student loans and early-career occupational choices," Journal of Public Economics, vol. 95(1-2), pp. 149-163, 2011.

C. Taber, "The rising college premium in the eighties: Return to college or return to unobserved ability," Review of Economic Studies, vol. 68(3), pp. 665-691, 2001.

I. Walker and Y. Zhu, "Differences by degree: Evidence of the net financial rates of return to undergraunder study for england and wales," Economics of Education Review, vol. 30(6), pp. 1177-1186, 2011.

D. Webber, "The lifetime earnings premia of different majors: Correcting for selection based on cognitive, noncognitive, and unobserved factors," Labour Economics, vol. 28, pp. 14-23, 2014.

_ - "Is the return to education the same for everybody?" IZA World of Labor, vol. 92, pp. 1-10, 2014. 
Figure 1: Cumulative Earnings Paths without Ability Correction

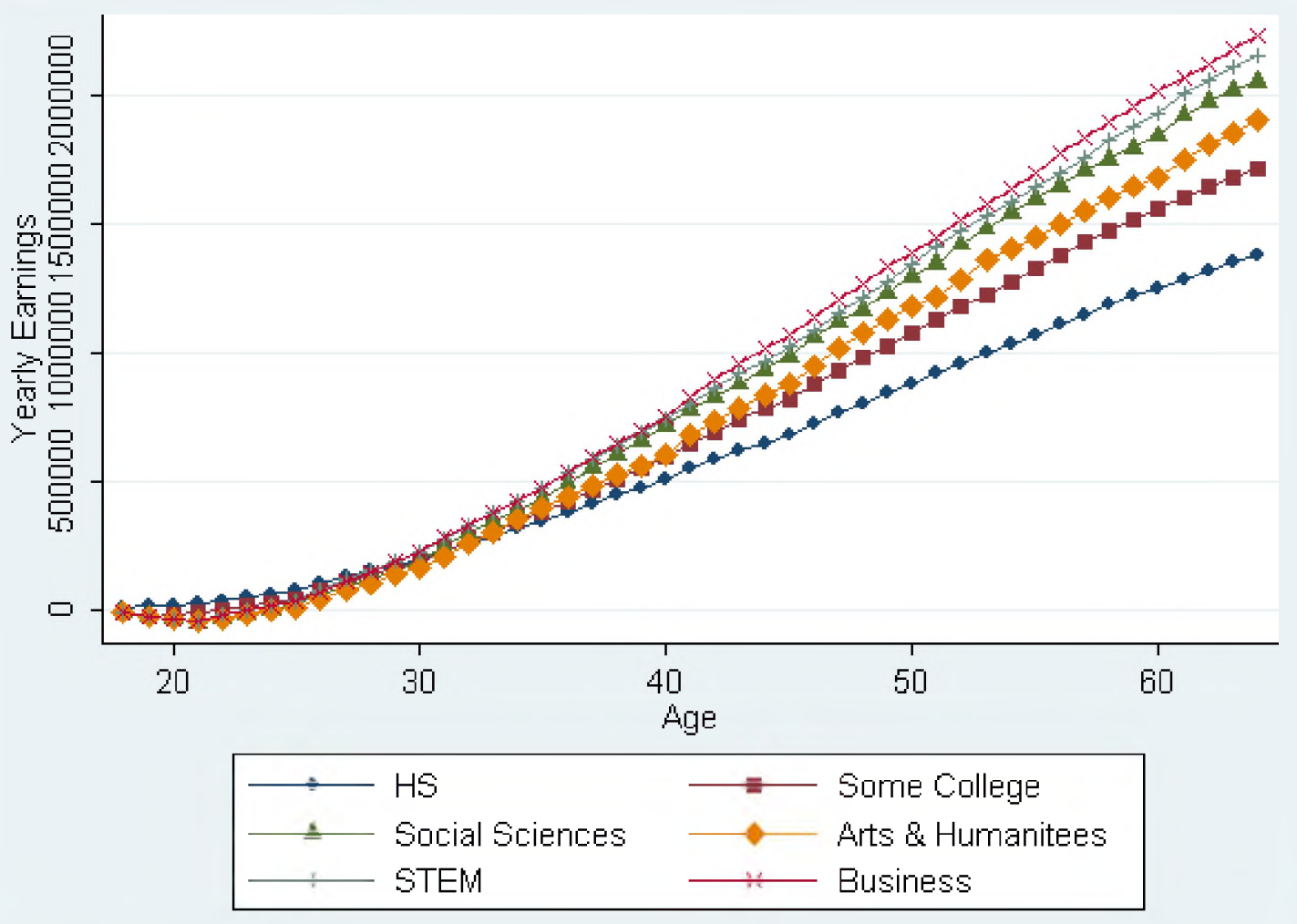


Figure 2: Cumulative Earnings Paths with Ability Correction

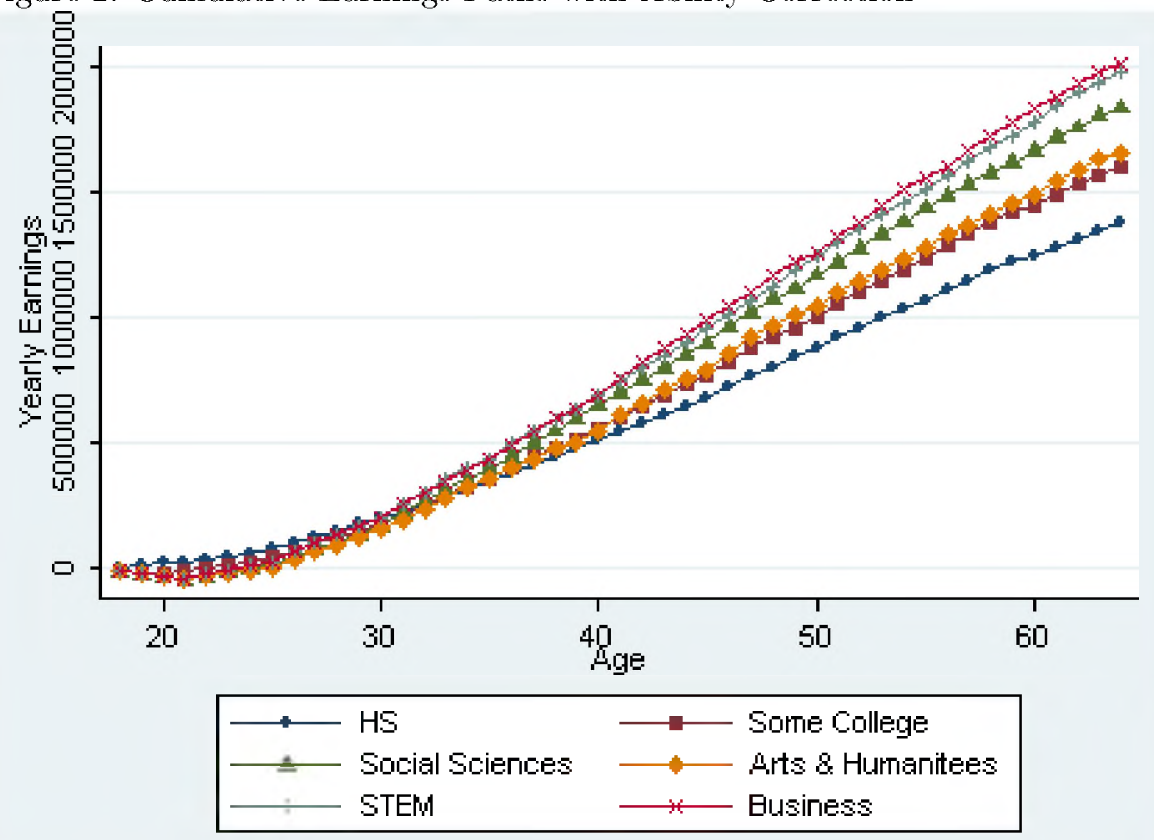


Figure 3: Cumulative Earnings Paths with Average College Costs and Debt

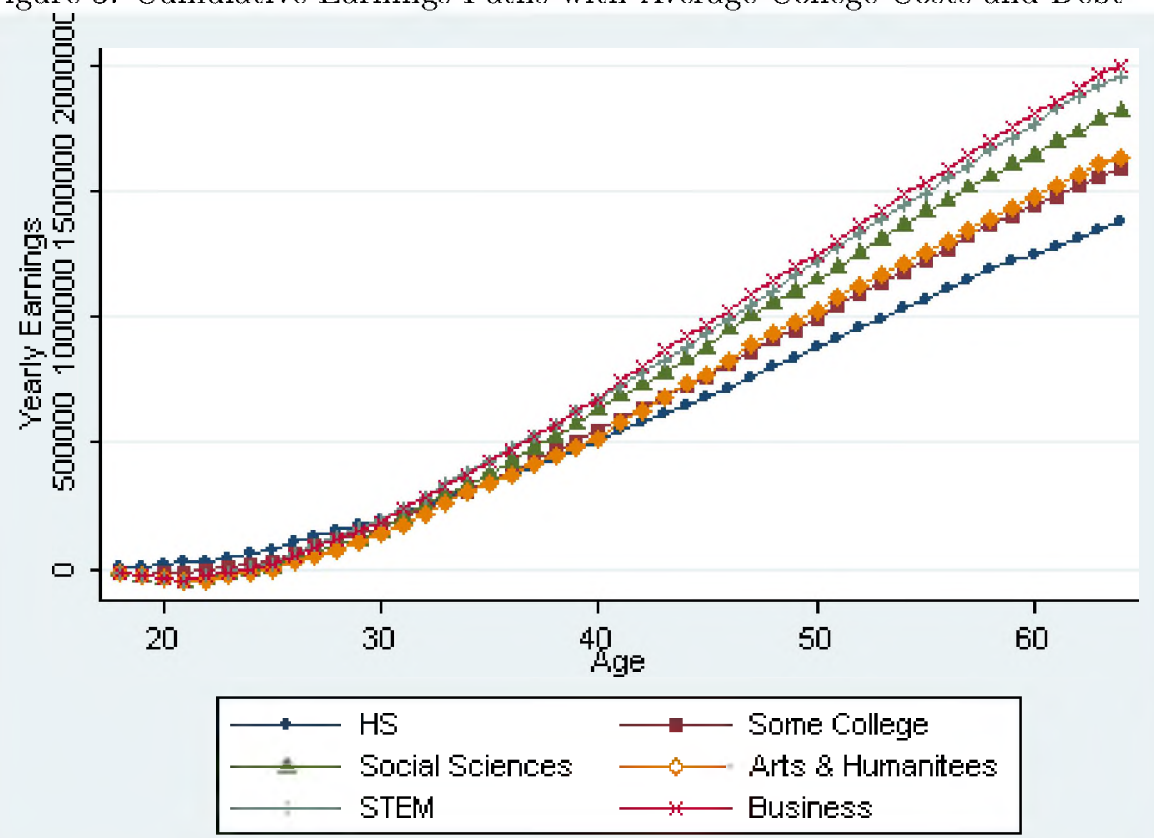


Figure 4: Cumulative Earnings Paths with Average College Costs and Debt

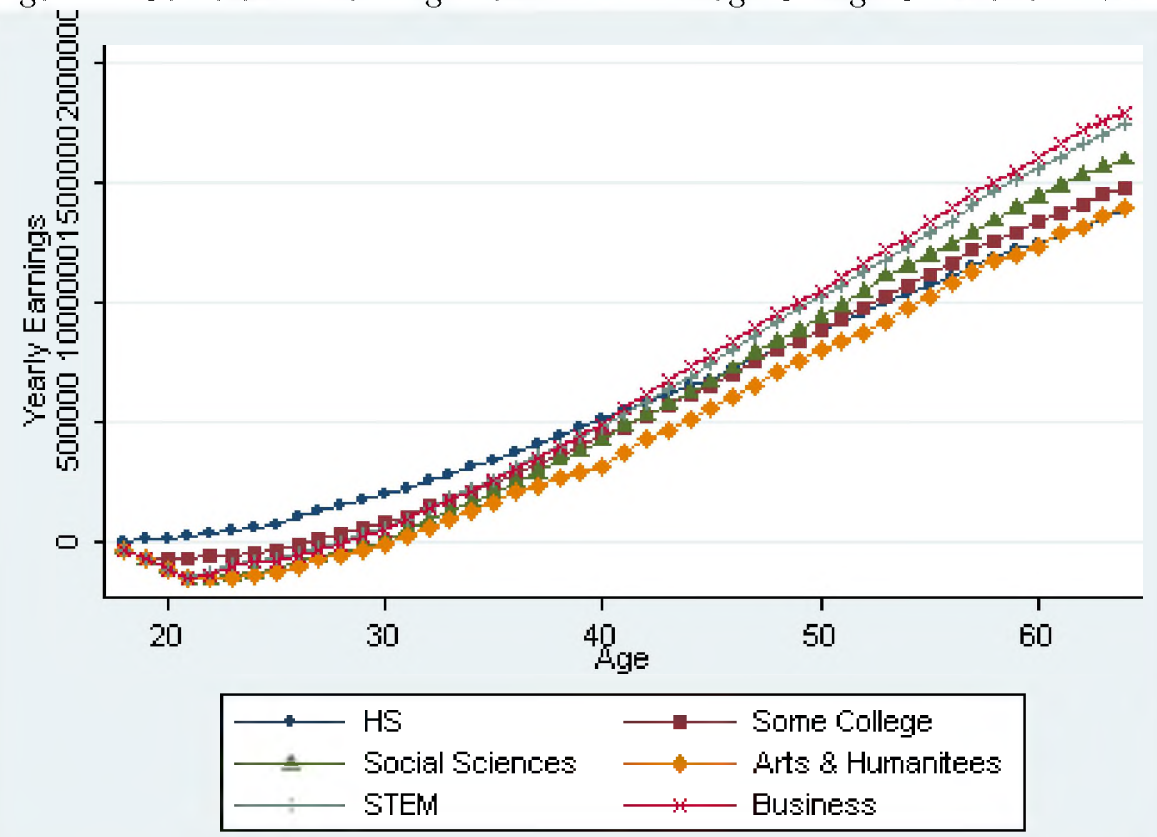


Figure 5: Likelihood of Educational Choice Being a Winning Financial Proposition (High College Costs)

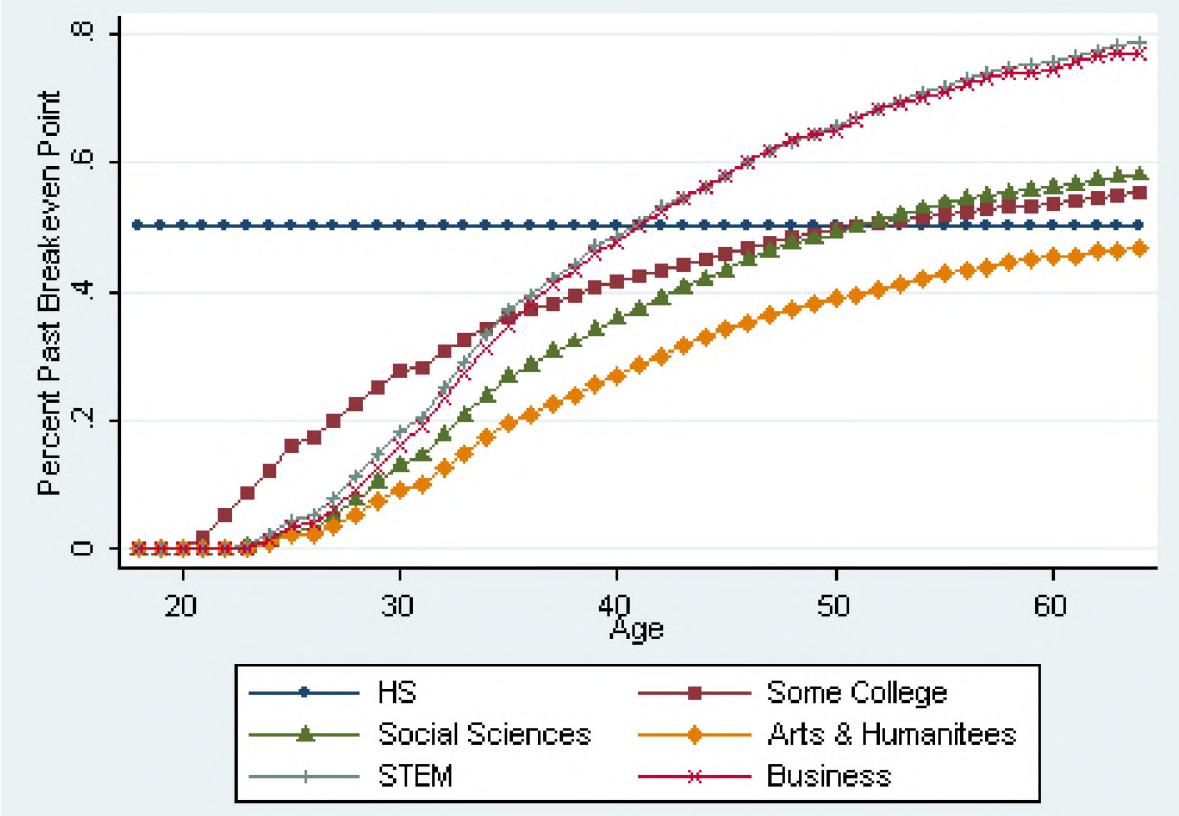


Table 1

Summary Statistics

\begin{tabular}{cccc}
\hline & NLSY & NSCG & ACS \\
\hline Black & .263 & .060 & .099 \\
Hispanic & .162 & .068 & .105 \\
High School & .548 & 0 & .355 \\
Some College & .299 & 0 & .385 \\
STEM & .043 & .406 & .066 \\
Business & .047 & .200 & .068 \\
Social Sciences & .012 & .106 & .027 \\
Arts and Humanities & .012 & .116 & .034 \\
Age 18-25 & .228 & .020 & .106 \\
Age 26-30 & .233 & .115 & .102 \\
Age 31-35 & .176 & .160 & .100 \\
Age 36-40 & .112 & .160 & .106 \\
Age 41-45 & .104 & .153 & .118 \\
Age 46-50 & .102 & .125 & .140 \\
Age 51-55 & .045 & .093 & .142 \\
Age 56-60 & 0 & .068 & .118 \\
Age 61-64 & 0 & .051 & .065 \\
Observations & 104,773 & 135,516 & 921,897 \\
\hline
\end{tabular}

The unit of observation in each sample is a person-year. Only individuals who have at least a high school diploma but no postgraduate work are retained in the sample. Individuals who are currently enrolled in college or the military, or who have no positive earnings over the past year, are excluded. 
Table 2

Simulated Expected Lifetime Earnings for the Median Individual

\begin{tabular}{ccccccc}
\hline & High & Some & STEM & Business & Social & Arts/Humanities \\
& School & College & & & Sciences & \\
\hline No selection correction & $1,376,504$ & $1,716,192$ & $2,155,404$ & $2,228,388$ & $2,051,532$ & $1,901,326$ \\
(1) with selection correction & $1,376,504$ & $1,597,248$ & $1,976,664$ & $2,014,222$ & $1,835,381$ & $1,659,094$ \\
(2) with average college expenses & $1,376,504$ & $1,588,789$ & $1,954,263$ & $1,993,428$ & $1,819,731$ & $1,626,686$ \\
(2) with high college expenses & $1,376,504$ & $1,479,237$ & $1,742,185$ & $1,786,306$ & $1,591,518$ & $1,393,856$ \\
\hline
\end{tabular}

Each value in the first four rows represents the median cumulative lifetime earnings as estimated from Equation (6) associated with each educational outcome given the assumptions listed in the first column. The results are obtained from a simulated sample of 100,000 individuals. All inputs to Equation (6) are obtained by estimating Equations (1) (5) with the conditions described in the first column. Bootstrapped standard errors for each model are small (roughly $\$ 10,000-\$ 20,000$ ), and are available upon request. 
Table 3

Simulated Expected Lifetime Earnings for an Individual at the 25th Percentile of the Ability Distribution

\begin{tabular}{ccccccc}
\hline & High & Some & STEM & Business & Social & Arts/Humanities \\
& School & College & & & Sciences & \\
\hline No selection correction & $1,260,121$ & $1,554,157$ & $1,749,691$ & $1,781,668$ & $1,707,343$ & $1,637,733$ \\
(1) with selection correction & $1,260,121$ & $1,446,937$ & $1,618,917$ & $1,639,607$ & $1,567,821$ & $1,462,501$ \\
(2) with average college expenses & $1,260,121$ & $1,435,240$ & $1,604,302$ & $1,626,487$ & $1,544,134$ & $1,444,065$ \\
(2) with high college expenses & $1,260,121$ & $1,313,536$ & $1,445,546$ & $1,464,426$ & $1,368,200$ & $1,252,691$ \\
\hline
\end{tabular}

Each value in the first four rows represents the median cumulative lifetime earnings as estimated from Equation (6) associated with each educational outcome given the assumptions listed in the first column. The results are obtained from a simulated sample of 100,000 individuals. All inputs to Equation (6) are obtained by estimating Equations (1)-(5) with the conditions described in the first column. Bootstrapped standard errors for each model are small (roughly $\$ 10,000-\$ 20,000$ ), and are available upon request. 
Table 4

Breakeven Ages with Selection Correction

\begin{tabular}{|c|c|c|c|c|}
\hline & STEM & Business & Social Sciences & Arts/Humanities \\
\hline \multicolumn{5}{|l|}{ Median ability } \\
\hline No college expenses & 30 & 30 & 32 & 34 \\
\hline Average college expenses & 31 & 31 & 32 & 35 \\
\hline High college expenses & 42 & 41 & 46 & 61 \\
\hline \multicolumn{5}{|l|}{25 th percentile ability } \\
\hline No college expenses & 30 & 31 & 33 & 36 \\
\hline Average college expenses & 32 & 32 & 36 & 39 \\
\hline High college expenses & 47 & 46 & 55 & - \\
\hline
\end{tabular}

Each entry represents the expected age at which in which cumulative earnings (subtracting off college costs) of individuals with a given degree at either the median or 25 th percentile of the ability distribution exceeds the cumulative earnings for a similar high school graduate with no college experience. Average college costs include $\$ 29,400$ of debt at graduation subject to a $3.4 \%$ interest rate, and roughly $\$ 4,000$ per year spent in college as costs which were not financed by a student loan. These figures are chosen to match recent debt, government student loan rates, and average public net tuition/fee statistics from the College Board. The high college costs include $\$ 60,000$ in average debt at graduation subject to an interest rate of $11 \%$, and roughly $\$ 15,000$ per year spent in college as costs which were not financed by a student loan. This level of debt corresponds roughly to the 90 th percentile of student loan debt with an interest rate offered by a private bank, and the costs correspond to a school with a net cost of $\$ 30,000$ per year. Bootstrapped standard errors for each model are small (roughly $2-.3$ years), and are available upon request. 
Table 5

Present Discounted Value of Degree

\begin{tabular}{ccccc}
\hline & STEM & Business & Social Sciences & Arts/Humanities \\
\hline Median ability & 514,031 & 544,323 & 390,345 & 225,515 \\
No Correction & 339,742 & 363,771 & 297,501 & 203,185 \\
Correct for Graduation Uncertainty & 259,623 & 274,519 & 200,553 & 94,819 \\
Correct for Graduation Uncertainty \& Ability & & & 220,654 \\
25th percentile ability & & & 326,319 & 144,071 \\
No Correction & 491,896 & 506,695 & 185,720 & 71,362 \\
Correct for Graduation Uncertainty & 211,582 & 226,980 & 119,586 & \\
\hline
\end{tabular}

Each entry represents the present discounted value assuming a discount rate of $3 \%$. The graduation uncertainty correction incorporates the probability that an individual attending college will not actually graduate (roughly $40 \%$ on average). The ability correction implements the procedure described in the text and are obtained by estimating Equations (1)-(5). 
Appendix Table 1

Simulated Expected Lifetime Earnings for the Median Individual (Males Only)

\begin{tabular}{|c|c|c|c|c|c|c|}
\hline & $\begin{array}{c}\text { High } \\
\text { School }\end{array}$ & $\begin{array}{c}\text { Some } \\
\text { College }\end{array}$ & STEM & Business & $\begin{array}{c}\text { Social } \\
\text { Sciences }\end{array}$ & Arts/Human \\
\hline No selection correction & $1,591,109$ & $1,961,700$ & $2,404,752$ & $2,417,057$ & $2,350,767$ & $2,017,453$ \\
\hline (1) with selection correction & $1,591,109$ & $1,828,417$ & $2,209,268$ & $2,194,433$ & $2,098,876$ & $1,785,026$ \\
\hline (2) with average college expenses & $1,591,109$ & $1,819,544$ & $2,188,368$ & $2,175,952$ & $2,082,676$ & $1,766,765$ \\
\hline (2) with high college expenses & $1,591,109$ & $1,719,301$ & $1,999,321$ & $1,990,561$ & $1,882,003$ & $1,562,113$ \\
\hline
\end{tabular}

Each value in the first four rows represents the median cumulative lifetime earnings as estimated from Equation

(6) associated with each educational outcome given the assumptions listed in the first column. The results are

obtained from a simulated sample of 100,000 individuals. All inputs to Equation (6) are obtained by estimating

Equations (1)-(5) with the conditions described in the first column. Bootstrapped standard errors for each model

are small (roughly $\$ 10,000-\$ 20,000$ ), and are available upon request. 
Appendix Table 2

Simulated Expected Lifetime Earnings for an Individual at the 25th Percentile of the Ability Distribution (Males Only)

\begin{tabular}{|c|c|c|c|c|c|c|}
\hline & $\begin{array}{l}\text { High } \\
\text { School }\end{array}$ & $\begin{array}{c}\text { Some } \\
\text { College }\end{array}$ & STEM & Business & $\begin{array}{c}\text { Social } \\
\text { Sciences }\end{array}$ & Arts/Humanities \\
\hline No selection correction & $1,455,710$ & $1,777,955$ & $1,980,900$ & $1,982,461$ & $1,953,043$ & $1,791,134$ \\
\hline (1) with selection correction & $1,455,710$ & $1,657,380$ & $1,837,425$ & $1,838,142$ & $1,799,076$ & $1,623,214$ \\
\hline (2) with average college expenses & $1,455,710$ & $1,646,392$ & $1,823,816$ & $1,827,003$ & $1,778,036$ & $1,612,540$ \\
\hline (2) with high college expenses & $1,455,710$ & $1,536,680$ & $1,669,227$ & $1,667,918$ & $1,605,219$ & $1,433,826$ \\
\hline
\end{tabular}

Each value in the first four rows represents the median cumulative lifetime earnings as estimated from Equation

(6) associated with each educational outcome given the assumptions listed in the first column. The results are obtained from a simulated sample of 100,000 individuals. All inputs to Equation (6) are obtained by estimating

Equations (1)-(5) with the conditions described in the first column. Bootstrapped standard errors for each model are small (roughly $\$ 10,000-\$ 20,000$ ), and are available upon request. 
Appendix Table 3

Breakeven Ages with Selection Correction (Males Only)

\begin{tabular}{|c|c|c|c|c|}
\hline & STEM & Business & Social Sciences & Arts/Humanities \\
\hline \multicolumn{5}{|l|}{ Median ability } \\
\hline No college expenses & 30 & 30 & 31 & 34 \\
\hline Average college expenses & 31 & 31 & 32 & 39 \\
\hline High college expenses & 41 & 41 & 43 & - \\
\hline \multicolumn{5}{|l|}{ 25th percentile ability } \\
\hline No college expenses & 30 & 31 & 33 & 38 \\
\hline Average college expenses & 32 & 32 & 35 & 39 \\
\hline High college expenses & 45 & 46 & 52 & - \\
\hline
\end{tabular}

Each entry represents the expected age at which in which cumulative earnings (subtracting off college costs) of individuals with a given degree at either the median or 25 th percentile of the ability distribution exceeds the cumulative earnings for a similar high school graduate with no college experience. Average college costs include $\$ 29,400$ of debt at graduation subject to a $3.4 \%$ interest rate, and roughly $\$ 4,000$ per year spent in college as costs which were not financed by a student loan. These figures are chosen to match recent debt, government student loan rates, and average public net tuition/fee statistics from the College Board. The high college costs include $\$ 60,000$ in average debt at graduation subject to an interest rate of $11 \%$, and roughly $\$ 15,000$ per year spent in college as costs which were not financed by a student loan. This level of debt corresponds roughly to the 90 th percentile of student loan debt with an interest rate offered by a private bank, and the costs correspond to a school with a net cost of $\$ 30,000$ per year. Bootstrapped standard errors for each model are small (roughly $.2-.3$ years), and are available upon request. 
Appendix Table 4

Simulated Expected Lifetime Earnings for the Median Individual (Females Only)

\begin{tabular}{|c|c|c|c|c|c|c|}
\hline & $\begin{array}{c}\text { High } \\
\text { School }\end{array}$ & $\begin{array}{c}\text { Some } \\
\text { College }\end{array}$ & STEM & Business & $\begin{array}{c}\text { Social } \\
\text { Sciences }\end{array}$ & Arts/Human \\
\hline No selection correction & $1,088,243$ & $1,377,821$ & $1,806,877$ & $1,916,595$ & $1,672,449$ & $1,606,744$ \\
\hline (1) with selection correction & $1,088,243$ & $1,285,758$ & $1,650,653$ & $1,728,515$ & $1,484,958$ & $1,417,316$ \\
\hline (2) with average college expenses & $1,088,243$ & $1,272,641$ & $1,629,268$ & $1,708,363$ & $1,467,560$ & $1,389,924$ \\
\hline (2) with high college expenses & $1,088,243$ & $1,153,636$ & $1,381,899$ & $1,478,688$ & $1,209,361$ & $1,116,672$ \\
\hline
\end{tabular}

Each value in the first four rows represents the median cumulative lifetime earnings as estimated from Equation

(6) associated with each educational outcome given the assumptions listed in the first column. The results are obtained from a simulated sample of 100,000 individuals. All inputs to Equation (6) are obtained by estimating

Equations (1)-(5) with the conditions described in the first column. Bootstrapped standard errors for each model are small (roughly $\$ 10,000-\$ 20,000$ ), and are available upon request. 
Appendix Table 5

Simulated Expected Lifetime Earnings for an Individual at the 25th Percentile of the Ability Distribution (Females Only)

\begin{tabular}{|c|c|c|c|c|c|c|}
\hline & $\begin{array}{c}\text { High } \\
\text { School }\end{array}$ & $\begin{array}{c}\text { Some } \\
\text { College }\end{array}$ & STEM & Business & $\begin{array}{c}\text { Social } \\
\text { Sciences }\end{array}$ & Arts/Humanities \\
\hline No selection correction & 995,659 & $1,247,644$ & $1,416,853$ & $1,473,019$ & $1,390,996$ & $1,370,154$ \\
\hline (1) with selection correction & 995,659 & $1,161,267$ & $1,313,009$ & $1,349,286$ & $1,267,923$ & $1,236,619$ \\
\hline (2) with average college expenses & 995,659 & $1,150,505$ & $1,299,134$ & $1,329,668$ & $1,251,382$ & $1,210,590$ \\
\hline (2) with high college expenses & 995,659 & $1,012,726$ & $1,118,311$ & $1,144,641$ & $1,034,008$ & 992,803 \\
\hline
\end{tabular}

Each value in the first four rows represents the median cumulative lifetime earnings as estimated from Equation

(6) associated with each educational outcome given the assumptions listed in the first column. The results are obtained from a simulated sample of 100,000 individuals. All inputs to Equation (6) are obtained by estimating

Equations (1)-(5) with the conditions described in the first column. Bootstrapped standard errors for each model are small (roughly $\$ 10,000-\$ 20,000$ ), and are available upon request. 
Appendix Table 6

Breakeven Ages with Selection Correction (Females Only)

\begin{tabular}{|c|c|c|c|c|}
\hline & STEM & Business & Social Sciences & Arts/Humanities \\
\hline \multicolumn{5}{|l|}{ Median ability } \\
\hline No college expenses & 30 & 30 & 33 & 34 \\
\hline Average college expenses & 31 & 31 & 35 & 37 \\
\hline High college expenses & 44 & 42 & 51 & 61 \\
\hline \multicolumn{5}{|l|}{25 th percentile ability } \\
\hline No college expenses & 31 & 31 & 35 & 36 \\
\hline Average college expenses & 33 & 33 & 37 & 38 \\
\hline High college expenses & 51 & 49 & 62 & - \\
\hline
\end{tabular}

Each entry represents the expected age at which in which cumulative earnings (subtracting off college costs) of individuals with a given degree at either the median or 25 th percentile of the ability distribution exceeds the cumulative earnings for a similar high school graduate with no college experience. Average college costs include $\$ 29,400$ of debt at graduation subject to a $3.4 \%$ interest rate, and roughly $\$ 4,000$ per year spent in college as costs which were not financed by a student loan. These figures are chosen to match recent debt, government student loan rates, and average public net tuition/fee statistics from the College Board. The high college costs include $\$ 60,000$ in average debt at graduation subject to an interest rate of $11 \%$, and roughly $\$ 15,000$ per year spent in college as costs which were not financed by a student loan. This level of debt corresponds roughly to the 90 th percentile of student loan debt with an interest rate offered by a private bank, and the costs correspond to a school with a net cost of $\$ 30,000$ per year. Bootstrapped standard errors for each model are small (roughly $.2-.3$ years), and are available upon request. 